\title{
Fabricação digital no Brasil e as possibilidades de mudança de paradigma no setor da construção civil
}

\author{
Digital fabrication in Brazil and the possibilities of \\ paradigma shift in the building sector
}

\section{Marina Ferreira Borges}

\section{Resumo}

A

proposta deste trabalho é analisar as possibilidades trazidas pelas tecnologias digitais emergentes em projeto arquitetônico e produção no canteiro para uma mudança de paradigma no setor da construção civil. Como metodologia propõe-se utilizar teóricos da economia evolucionista, que colocam a inovação como um agente central para as mudanças de paradigmas, para visualizar as conexões entre firmas existentes no paradigma atual, a manufatura e as conexões que poderiam ser estabelecidas para um novo paradigma de produção por meio da fabricação digital. Para isso também será analisado o papel da universidade e seu potencial de inovação, tanto no sentido de desenvolver tecnologia de produtos, quanto de contextualizar a tecnologia que está sendo importada para um contexto regional, desenvolvendo processos de produção emancipatórios para a construção civil.

Palavras-chaves: Construção civil. Fabricação digital. Teoria econômica evolucionista. Sistema setorial de inovação.

\footnotetext{
Abstract

This paper analyses the possibilities brought by new digital technologies, architectural design and production for a paradigm shift in the construction sector. The methodology proposes to use evolutionary economy theory, which sees innovation as a key agent for paradigm shifts, to visualise the connections between existing firms in the current paradigm and the connections that could be established for a new production paradigm through digital fabrication. In order to do this, the role of the university and its innovation potential will also be analysed, both to develop product technology and to contextualize the technology being imported into a regional context, developing an emancipatory production process for the construction industry.

Keywords: Building construction. Digital fabrication. Evolutionary economy theory. Sectoral innovation system.
}

Marina Ferreira Borges Universidade Federal de Minas Gerais Belo Horizonte - MG - Brasil

Recebido em 21/03/16 Aceito em 06/06/16

BORGES, M. F. Fabricação digital no Brasil e as possibilidades de mudança de paradigma no setor da construção civil. 79 Ambiente Construído, Porto Alegre, v. 16, n. 4, p. 79-91, out./dez. 2016. 


\section{Introdução}

A fabricação digital é um tipo de produção de objetos físicos a partir de modelos digitais, cujos dados são enviados diretamente para equipamentos controlados numericamente, eliminando etapas intermediárias de produção. A fabricação digital já existe deste a década de 1950, tendo sido largamente utilizada na produção de componentes para a indústria aeronáutica e automobilística. Devido ao avanço desse tipo de maquinário nas últimas décadas e a redução de custo dos equipamentos, esse processo de fabricação começou a ser empregado na construção civil a partir do aperfeiçoamento de tecnologias de projeto dos sistemas CAD, do inglês computeraided design, e das tecnologias de fabricação dos sistemas CAM, do inglês computer-aided manufacturing. A automatização do projeto em arquitetura tem aberto novas possibilidades de projeto e produção. Segundo Kolarevic (2003), a era digital possibilita que os arquitetos retomem a autoridade que um dia tiveram na produção de edifícios, não apenas no seu design, mas também na sua construção, com domínio pleno sobre as decisões do processo construtivo. Mas, para alguns teóricos como Pedro Arantes (2012), o pensamento de Kolarevic representa uma ilusão de que estaria sendo reconstituída a "unidade perdida" entre o desenho e o canteiro. Sendo assim, o objetivo deste artigo é analisar se a fabricação digital pode representar uma mudança das relações econômicas de produção por meio de ferramentas digitais de projeto e produção como pressupõe Kolarevic, ou se a crítica de Arantes se faz mais pertinente analisando o contexto econômico brasileiro.

Como metodologia serão analisadas as relações de produção na construção civil por meio da teoria econômica evolucionista, em que a inovação é considerada um fenômeno central para mudanças de paradigmas. Para tanto, serão avaliadas as relações dos profissionais de arquitetura e dos profissionais de engenharia (que detêm atualmente o controle da produção) no paradigma da manufatura, e posteriormente as possíveis relações que seriam construídas em um paradigma de fabricação digital em uma reordenação do processo produtivo.

Nas universidades brasileiras, algumas tentativas de se entrar nesse novo paradigma vêm sendo feitas, principalmente no campo da pesquisa científica. As faculdades de arquitetura têm importado máquinas, criado laboratórios de fabricação de digital, e, mesmo que de maneira ainda incipiente, preparado arquitetos para projetar nesse novo paradigma. Mas seriam essas iniciativas suficientes para modificar as relações de produção da construção civil no Brasil? Elas representam uma verdadeira possibilidade de inovação no campo? Como essas novas possibilidades de produção podem ser utilizadas para se ampliar o espectro de atendimento social? Para Ferro (2002 ${ }^{1}$ apud NOBRE; STOLFI; REZENDE, 2002), jamais se deve abandonar a conquista da razão, do saber, do pensamento humano, que são fundamentais, mas em cada caso é preciso analisar, criticar e reutilizar com outro sentido, sendo, portanto, fundamental se fazer uma revisão crítica na importação de processos tecnológicos para o contexto regional.

\section{Inovação na economia}

Como método de análise das relações de produção na construção civil será utilizada a teoria econômica evolucionista, pois nela a inovação é considerada um fenômeno central, inerente à economia capitalista com efeitos desequilibradores fundamentais. A teoria econômica evolucionista pode auxiliar na compreensão da inovação com o estabelecimento de novos paradigmas tecnológicos dentro de um setor.

Economistas clássicos como Adam Smith e Marx já falavam a respeito do papel da inovação no desenvolvimento econômico. Em 1776, Adam Smith refletiu sobre uma nova forma de organização devido à mudança de manufatura para a industrialização. Ele afirma que o progresso econômico acontece pelas possibilidades de aumento da produtividade e ampliação de mercados por meio da especialização e simplificação das funções produtivas em que a mecanização da função trazia inovação ao processo (CASTRO; CARVALHO, 2008). Em $O$ Capital, Marx (1996) diz que o capitalismo só consegue sobreviver à custa de renovar suas bases tecnológicas o tempo todo, em que a combinação social do processo de produção é a introdução da inovação tecnológica com a mais-valia e o lucro.

Em 1911, Schumpeter (1985) recuperou as ideias clássicas de desenvolvimento, mudanças descontínuas e progresso técnico. Para ele, para que a economia saia de um estado de equilíbrio e inicie um novo ciclo de desenvolvimento, é necessário que se introduza algum tipo de inovação. Schumpeter coloca que para se introduzir uma inovação é necessário que se introduza um novo produto, um novo método, que se abra um novo mercado, que se conquiste novas

${ }^{1}$ Entrevista concedida a Nobre, Stolfi e Rezende (2002). 
fontes de matéria-prima ou sejam implementadas inovações organizacionais.

A partir das ideias de Schumpeter, surgiu uma literatura com um caráter específico e setorial do progresso técnico. Os neo-schumpeterianos incorporam a análise das instituições (empresas, universidades e governo) como agentes de mudanças estruturais de um sistema econômico, segundo o qual os sistemas nacionais de inovação e as políticas tecnológicas são indutores do desenvolvimento. Para Freeman e Soete (1997), os neo-schumpeterianos possuem metodologias de análise que relacionam o contexto social, econômico, tecnológico e institucional para explicar a trajetória de um sistema econômico, tendo a inovação como principal agente de mudanças.

Nos países periféricos, o acesso à ciência e tecnologia é mais difícil, sendo as raízes do atraso científico as mesmas do subdesenvolvimento econômico, havendo uma diferença de percurso entre países centrais e periféricos para uma nova tecnologia em um mesmo setor. Os países periféricos tendem a trabalhar com imitação da inovação, o que diminui seus riscos com a incerteza, mas a transferência de uma tecnologia física somente não é suficiente para que a revolução tecnológica se traduza em um novo paradigma. Para Nelson (2008), não basta impor uma tecnologia física sem a construção de uma tecnologia social.

Nelson (2008) afirma que a tecnologia social envolve a criação de uma infraestrutura de difusão da tecnologia na qual são criados métodos em contextos nos quais ações e interações das partes determinam o que é encontrado. Essas partes são compostas de leis, normas, expectativas, mecanismos de governança e comportamentos habituais. A inovação depende da interação da tecnologia física com a social, mas a tecnologia social não pode ser importada, sendo muito mais difícil inovar pela imitação. Para Abramovitz (1989), as instituições são capazes de conseguir a combinação necessária de mudanças técnicas e sociais. As universidades são centrais na construção do conhecimento e na difusão da inovação social relacionada. Para Nelson (1993), a universidade enquanto lugar de pesquisa e ensino reflete ou molda as indústrias.

Nos setores industriais, o progresso tecnológico é visto como um dos elementos principais do processo de transformação, o que permite o aumento da produtividade e a redução de custos na maioria dos setores. Mas o setor da construção civil, principalmente no Brasil, é vinculado a um "atraso tecnológico" por ainda não ter conseguido entrar num paradigma industrial e ainda estar vinculado a uma produção manufaturada. Farah (1994) justifica essa perspectiva de atraso do setor como uma tendência de não se considerar as articulações entre a indústria da construção e o processo de acumulação.

Para analisar as relações entre firmas ${ }^{2}$ na construção civil posicionando o lugar dos arquitetos no contexto da produção, este artigo propõe utilizar as conexões propostas pelo economista inglês Pavitt (1984) (pioneiro na criação de novos métodos para mensurar inovação e mudança tecnológica), que mapeiam o fluxo econômico entre firmas em um setor, de tal maneira que se compreenda as relações e as possibilidades de inovação que cada agente representa (Figura 1).

Pavitt (1984) chama de "firmas dominadas por fornecedores" aquelas que dependem de fornecedores para uma produção manufatureira tradicional. Na construção civil, podemos dizer que essa "firma" é representada pelo canteiro de obras, local da produção altamente dependente de outros agentes fornecedores. No canteiro, a inovação está mais vinculada aos processos, mas por ser altamente dependente de outros fatores seu potencial de inovar é baixo, estando sempre a inovação vinculada a uma redução de custos. As "firmas intensivas em escala" são as indústrias que fornecem materiais e equipamentos para a produção. Seu potencial de inovação em processos é alto devido à organização industrial da produção. Os "fornecedores especializados" serão considerados para análise do setor da construção, os fornecedores de projetos, que no caso é representado por projetos de arquitetura e engenharia. Esses fornecedores inovam predominantemente em produtos, e, por geralmente se organizarem em pequenas firmas, seu potencial de inovação é baixo. E, finalmente, "as firmas baseadas em ciência", como os institutos de pesquisa e as universidades, são as instituições que trabalham com pesquisa e desenvolvimento. Para a construção civil, considera-se somente o papel da universidade nos processos. Seu potencial de inovação é alto tanto com relação a processos quanto com relação a produtos, tendo dessa maneira um papel fundamental para promover a inovação em um setor.

\footnotetext{
${ }^{2}$ Para a economia, de acordo com a Teoria da Firma, firmas ou empresas são organizações que produzem e vendem bens e serviços, e contratam e utilizam fatores de produção. As firmas reúnem o capital e o trabalho para a produção, agregando valor às matérias-primas mediante uso de tecnologias.
} 
Figura 1 - Conexões entre diferentes categorias de firmas em um setor

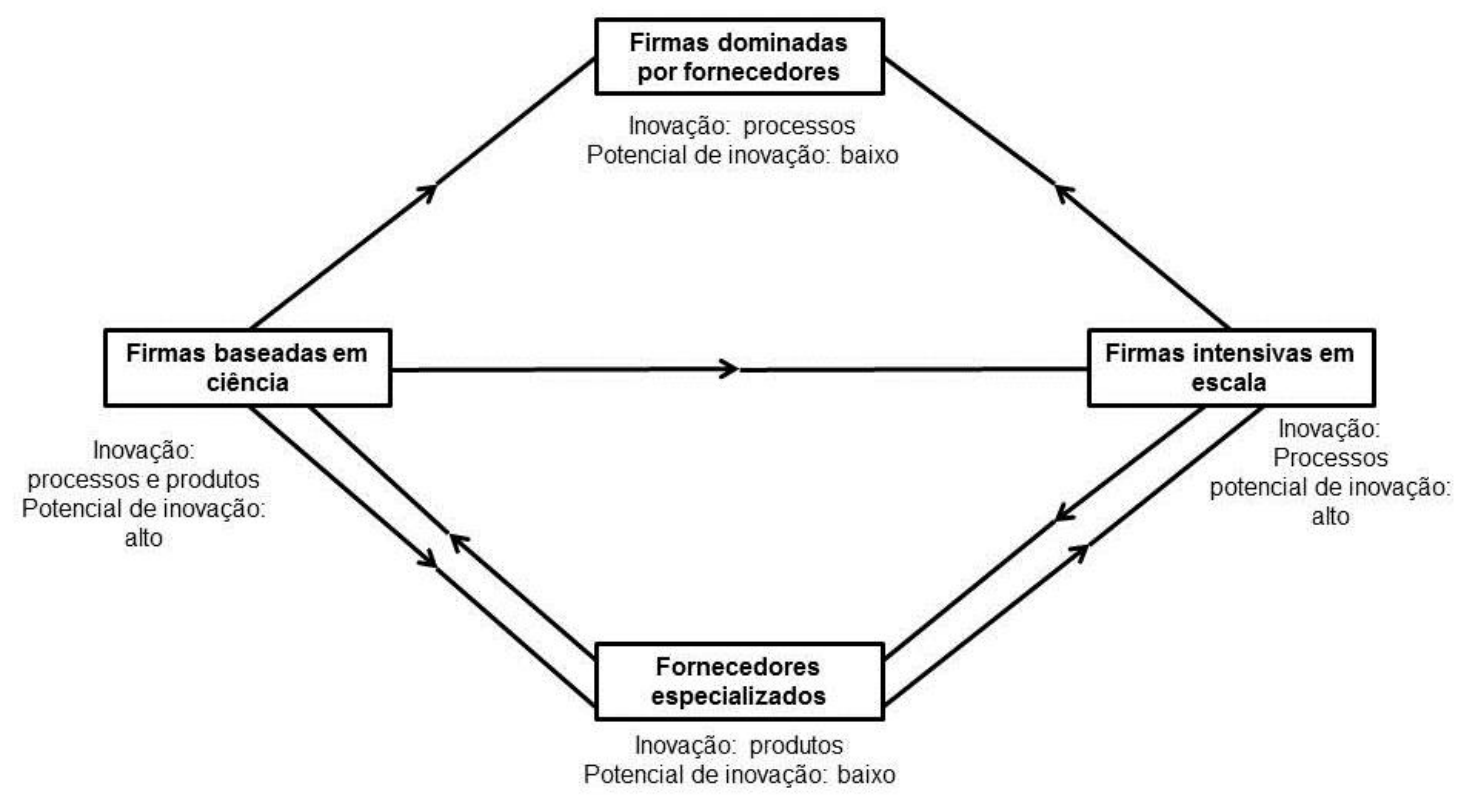

Fonte: adaptado de Pavitt (1984).

A análise das relações de produção no setor da construção civil será feita para o paradigma da manufatura considerando o posicionamento atual dos arquitetos e o posicionamento dos engenheiros, detentores do controle da produção, principalmente em canteiros maiores e com características mais industriais. Para um possível paradigma da fabricação digital, serão consideradas as novas relações de projetos e as conexões entre firmas que poderiam ser construídas. Dessa maneira, pode-se discutir se a fabricação digital no Brasil pode vir a representar novas construções de relações tendo o arquiteto como agente fundamental para o controle da produção ou se a introdução dessas tecnologias será insuficiente para a retomada preconizada por Kolarevic (2003).

\section{Paradigmas da construção civil}

\section{Manufatura}

Para Ferro $\left(2002^{3}\right.$ apud NOBRE; STOLFI; REZENDE, 2002), a arquitetura no Brasil é produzida de uma maneira bastante elementar, uma manufatura cuja lógica data do século XV, na Europa, mas que até hoje se mantém sem grandes transformações, apesar dos esforços dos que procuram a industrialização da construção. Ferro diferencia a produção em manufatura, dividindo os processos em manufatura serial e manufatura heterogênea. A manufatura serial corresponde a uma sucessão acumulativa de equipes de produção que executam as tarefas no canteiro. A manufatura heterogênea se refere à montagem de peças industrializadas no canteiro e que não obedece a uma sucessão acumulativa de trabalho. A manufatura serial está presente predominantemente em canteiros menores, onde não existe um interesse em se aperfeiçoar processos produtivos para uma lógica industrial. Nos canteiros maiores, há um predomínio da manufatura heterogênea, em que o objetivo é obter processos quase industriais de produção para a redução de custos.

Em 1930, Le Corbusier preconizou a experiência fordista como lição aos arquitetos modernos, em que o domínio da técnica consistia em: domínio da técnica em si, domínio sociológico (uma nova casa e uma nova cidade para uma nova época), e o domínio econômico, que seria a necessidade de trazer para a arquitetura a padronização, a industrialização e a taylorização (SHIMBO, 2010). $\mathrm{A}$ arquitetura moderna pressupunha uma mudança social aliada à produção industrial da habitação a partir do projeto de uma nova sociedade. Nesse pressuposto, a arquitetura ganhava uma centralidade como meio de uma nova ordem social, econômica e cultural das edificações e das cidades. Para essa perspectiva era necessário um novo repertório de formas, uma nova técnica e uma nova proposta social. Do ponto de vista econômico, relacionando com as ideias de Schumpeter (1985), o que Le Corbusier propunha era a instalação de um novo paradigma por meio

${ }^{3}$ Entrevista concedida a Nobre, Stolfi e Rezende (2002). 
da inovação de produtos, métodos e de inovações organizacionais.

Após a Segunda Guerra, países da América do Norte e Europa passaram a ter uma ampla utilização de componentes pré-fabricados, de tal maneira que se diminuísse o tempo de construção e o custo da mão de obra. No Brasil, os preceitos modernistas foram estabelecidos apenas como a inovação no sentido da criação de um novo repertório de formas. Ferro $\left(2002^{4}\right.$ apud NOBRE; STOLFI; REZENDE, 2002) acreditava que a euforia desenvolvimentista havia sido prejudicial na medida em que tentava adequar nossa realidade a um futuro industrial que não se confirmava.

Na década de 1970, o governo brasileiro estimulou inovações tecnológicas no setor da construção, com tentativas de introduzir elementos préfabricados na dinâmica do canteiro. Máquinas foram importadas, mas não foi criada uma política industrial capaz de coordenar os ciclos de produção (KOURY, 2005). Segundo Farah (1994), no Brasil houve uma "nova" concepção de industrialização da construção, em que a préfabricação com sistemas fechados como ocorria nos países centrais foi traduzida em uma montagem de componentes industrializados no canteiro, caraterizados por sistemas abertos e flexíveis. Sendo assim, o sistema se aproximou mais de um processo de manufatura heterogênea do que efetivamente de um processo de industrialização da construção. Dessa maneira, no Brasil nunca foi desenvolvido um processo efetivamente industrial da construção, tendo apenas a presença de componentes e processos industrializados em canteiros de manufatura heterogênea. A manufatura heterogênea procura uma padronização do processo construtivo, com ciclos mais rápidos de construção. Embora não seja considerada uma produção industrial, procurase uma escala industrial de produção com elevado grau de especialização dos processos.

Mas, embora sejam utilizados insumos produzidos com alta tecnologia na manufatura heterogênea, o processo produtivo é descontínuo. Além disso, existe um preconceito com relação à mão de obra, que é considerada desqualificada, reforçando o caráter de exploração do trabalho como uma das formas de se obter mais-valia. Esses fatores dificultam o desenvolvimento tecnológico do setor, inibindo qualquer inovação de processos no canteiro. Shimbo (2010) afirma que o canteiro impõe uma lógica de produção que perpassa as etapas clássicas da modernidade industrial. $\mathrm{Na}$ construção civil, o produto é consumido onde ele é fabricado, tendo um deslocamento constante da

${ }^{4}$ Entrevista concedida a Nobre, Stolfi e Rezende (2002). produção. Ele não corresponde a uma fábrica, com local prévio e definido. Sua complexidade de organização e produção vem da particularidade de suas características: embora não seja artesanato, conserva alguns pontos em comum com esse modo de produção; embora não seja totalmente uma manufatura, apresenta uma racionalidade semelhante; e, embora não possa ser considerado indústria, utiliza elementos industrializados e se vale de inovações tecnológicas de maquinário e componentes.

É devido à incompreensão das especificidades do seu modo de produção que Arantes (2012) afirma que as tentativas de industrialização fordista na construção civil foram inúmeras e quase sempre fracassadas. Houve transformações nos materiais, nas modulações e na padronização de projetos, mas mesmo a pré-fabricação parcial de componentes não altera a condição produtiva do canteiro. O canteiro continuou caracterizado por uma variação de produtos (obras) e locais da produção, o que torna improvável o estabelecimento de séries estáveis de postos de trabalho taylorizados, além de uma irregularidade na continuação das tarefas, o que dificulta uma programação precisa do trabalho.

O papel da arquitetura nesse modo de produção que visa à produção em escala é a de padronizar os produtos. A figura do arquiteto praticamente desaparece do ambiente do canteiro. Os arquitetos não têm nenhuma influência sobre os métodos empregados na construção. Para o emprego de uma produção em escala industrial, é necessário que exista uma produção em escala e, para tanto, cabe aos arquitetos definirem um produto que tenha características de adaptabilidade a vários contextos. Sendo assim, segundo Shimbo (2010), as edificações perdem os pressupostos básicos de arquitetura, tais como orientação solar, implantação em conformidade com o perfil do terreno e uma relação equilibrada entre forma, função e materialidade. Dessa maneira, tem-se uma simplificação do trabalho do arquiteto para atender a uma escala industrial de produção.

Analisando o papel dos arquitetos na produção em manufatura heterogênea nas conexões entre firmas propostas por Pavitt (1984), podemos perceber a ausência de algumas importantes relações que relegam a arquitetura a um papel pouco relevante na produção como um todo (Figura 2).

Embora o projeto de arquitetura oriente a produção da forma no canteiro, os arquitetos não conseguem estabelecer uma relação mais atuante na relação com os outros agentes. Sua relação com a indústria de materiais e equipamentos é unilateral, não havendo desenvolvimento de produtos nem de 
equipamentos para o fornecimento e orientação da produção. Dessa maneira, os arquitetos especificam em seus projetos elementos industriais existentes, o que faz com que não haja inovação de processos, havendo assim apenas propostas de tipologias arquitetônicas diferentes. A universidade, considerando nesse caso as escolas de arquitetura, tem uma relação estreita com a produção arquitetônica feita pelo mercado. Obras construídas são analisadas sobre uma perspectiva crítica, e uma nova geração de mão de obra de arquitetos é formada sobre essa perspectiva, mas as escolas de arquitetura no contexto atual brasileiro não desenvolvem de maneira relevante pesquisas para o desenvolvimento de novos materiais, nem de processos inovadores para orientar a produção no canteiro. Sendo assim, essas conexões acabam sendo dominadas pelas escolas de engenharia (Figura 3).

Figura 2 - Papel da arquitetura na produção em manufatura heterogênea na construção civil baseado nas conexões de Pavitt (1984)

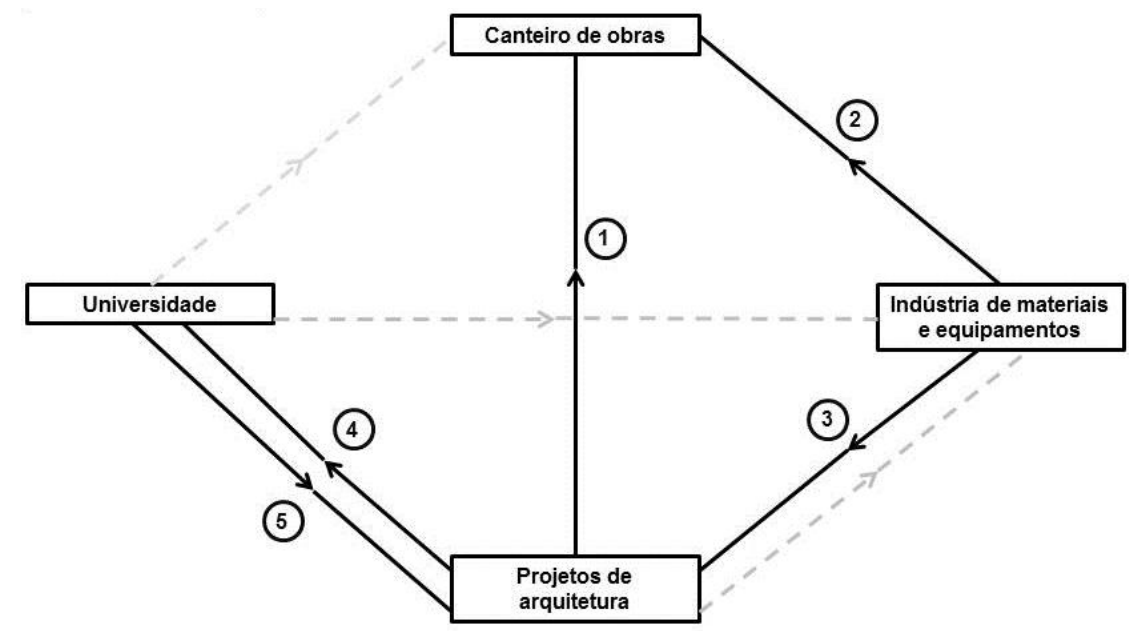

\footnotetext{
1 Projetos de arquitetura orientam a construção da forma

2 Fornecimento de materiais e equipamentos

3 Projetos de arquitetura especificam materiais existentes na indústria

4 Universidade estuda projetos arquitetônicos

5 Universidade fornece mão-de-obra para o mercado
} 
Figura 3 - Papel da engenharia na produção em manufatura heterogênea na construção civil baseado nas conexões de Pavitt (1984)

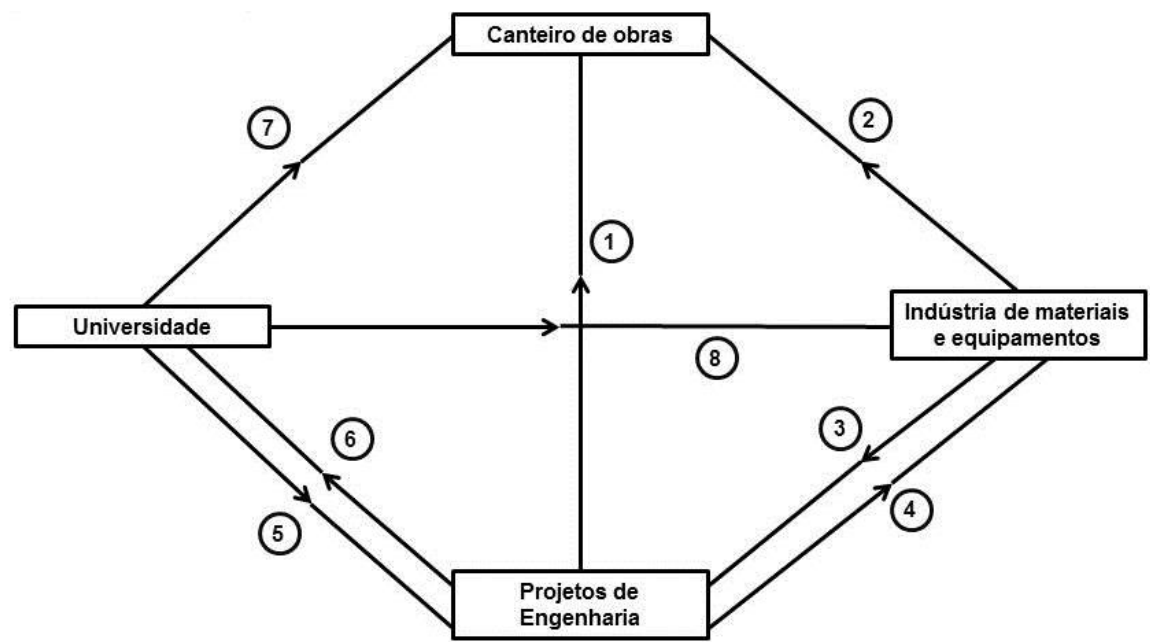

1 Projetos de engenharia (estrutura e instalações) orientam a construção

2 Fornecimento de materiais e equipamentos

3 Projetos de engenharia especificam materiais existentes na indústria

4 Projetos de engenharia para materiais e equipamentos

5 Universidade fornece mão-de-obra para o mercado

6 Universidade estuda projetos de engenharia

7 Pesquisa de processos de gestão para o canteiro

8 Universidade desenvolve novos produtos e equipamentos

Fonte: desenvolvido a partir da figura de Pavitt (1984).

As escolas de engenharia ${ }^{5}$ têm conexões importantes tanto com a indústria como com o canteiro de obras. Com o objetivo de diminuir custos da produção, as pesquisas desenvolvem processos gerenciais que procuram uma maior racionalidade e eficiência para a execução das tarefas. A universidade também dialoga muito bem com a indústria, desenvolvendo pesquisas de materiais e equipamentos para a melhoria de processos e produtos. Os escritórios de projeto também desenvolvem pesquisas em conjunto com a indústria e a universidade. Com o objetivo comum de se reduzir custos e aumentar os lucros, toda a inovação desde o projeto até a produção é direcionada para uma otimização de tempo de produção e barateamento dos materiais. Dessa forma, os engenheiros têm atualmente uma posição mais consolidada no processo produtivo, sendo agentes mais ativos em toda a dinâmica do setor no paradigma existente.

\section{Fabricação digital}

A fabricação digital em arquitetura é um fenômeno recente, que emergiu nos últimos 15 anos, quando os processos computacionais de projeto em softwares CAD e os processos de produção CAM

${ }^{5}$ Neste caso não será considerado considerar apenas a engenharia civil, mas todas as engenharias, tais como mecânica, elétrica, de produção, de materiais e de automação, que também fazem parte do contexto da produção no canteiro de obras. tornaram-se importantes objetos para o debate crítico da prática profissional e da educação no campo da arquitetura. $\mathrm{Na}$ fabricação digital, o projeto é desenvolvido como um modelo tridimensional e suas partes componentes são produzidas utilizando um processo de produção automatizada em máquinas específicas de controle numérico (CNC), que transformam uma informação digital em um modelo físico (protótipo ou peças componentes customizadas em escala 1:1 para a montagem do próprio edifício). O objeto produzido contém todos os dados do modelo computacional, reproduzindo com grande precisão o detalhamento proposto em projeto.

Até a crise de 2008, as tecnologias digitais de projeto e produção significaram um aumento de possibilidades formais para obras que necessitavam de um valor simbólico para se diferenciarem como "marcas exclusivas" em um contexto global. A fabricação digital teve um papel fundamental na produção de edifícios de formas complexas que não seriam exequíveis sem o desenvolvimento do maquinário adequado. Os projetos do arquiteto Frank Gehry, especialmente o Guggenheim de Bilbao, representaram um ponto de inflexão no uso das tecnologias CAD/CAM no começo dos anos 2000. Outros arquitetos de elite também exploraram as possibilidades para a criação de formas inéditas. Nesse período, o principal campo de exploração da fabricação 
digital e tecnologias digitais emergentes de projeto estiveram associados a obras de produção restrita e simbólicas no contexto das cidades em que estavam sendo inseridas.

Segundo Ferro (2002 ${ }^{6}$ apud ARANTES, 2012), na arquitetura contemporânea as ferramentas digitais de projeto permitiram uma autonomia formal, em que o gesto artístico antes irrealizável tornou-se processo produtivo factível no canteiro, mas, embora muitas das obras de capital simbólico tenham utilizado processos de fabricação digital, este não significou uma transformação na produção. $\mathrm{Na}$ maioria das obras o canteiro teve uma produção híbrida, com o trabalho artesanal de montagem atuando em conjunto com a fabricação digital de componentes customizados para a edificação. Em locais onde era possível obter a mão de obra mais barata, em especial na China, onde foram construídos nos últimos anos diversos projetos de arquitetos do "star-system", os processos se tornavam mais artesanais, mesmo com projetos de alta tecnologia. Sendo assim, a inovação tecnológica de projetos não foi acompanhada por uma inovação tecnológica no espaço da produção. $\mathrm{O}$ canteiro manteve a mesma lógica da manufatura e da mais-valia da mão de obra.

Para Arantes (2012), a arquitetura na era digitalfinanceira ampliou enormemente o repertório de formas e técnicas à sua disposição, mas essa arquitetura é reduzida a um mero significante, sem regras e limitações de qualquer espécie em busca de um grau máximo de renda. Dessa maneira, percebe-se que mesmo com o avanço da tecnologia para a produção de formas complexas, os arquitetos não mobilizaram a seu favor as qualidades físicas, construtivas e plásticas dos materiais, como também desconsideraram o trabalho e os trabalhadores do canteiro.

Após a crise de 2008, houve uma redução da construção de projetos espetaculares, primeiro devido à própria crise financeira nos países centrais, e segundo por certo esgotamento do modelo de diferenciação de cidades pela arquitetura icônica. Os grandes escritórios que trabalhavam nesses projetos começaram a vislumbrar as possibilidades de utilização e transformação no uso das tecnologias de modelagem para trabalhar no sentido de se evitar o desperdício e o excesso. Dessa maneira, começouse a pensar em uma arquitetura menos focada na forma inédita e mais na demonstração de seu desempenho ambiental, construtivo e social. Para
Arnold Walz (2014 ${ }^{7}$ apud SEDREZ; CELANI, 2014, p. 3),

\section{[...] nós devemos tentar usar essa experiência e aproximá-la da arquitetura comum; isso significa que nós temos que desenhar novos processos construtivos $e$ novas maneiras de fabricar elementos construtivos [...].}

$\mathrm{Na}$ América Latina, com a redução dos custos de aquisição dos equipamentos e a quebra de algumas patentes, começaram a emergir laboratórios de fabricação digital - os chamados Fab Labs - mas a princípio com o propósito de produzir pequenos objetos em impressoras 3D. O Massachusetts Institute of Technology (MIT) foi o responsável pela difusão da tecnologia com a implantação dos primeiros laboratórios no Brasil. Sua rede de Fab Labs tem atualmente 250 laboratórios espalhados pelo mundo, dos quais $5 \%$ estão localizados na América Latina. Segundo Sperling, Herrera e Scheeren (2015), os desafios de implementação no Brasil e na América Latina estão associados à criação de uma cultura de inovação, à substituição do pensamento competitivo (muito presente em ambientes com baixo grau de inovação) por um pensamento colaborativo, e, por fim, à otimização de fatores econômicos e administrativos, tais como a redução de burocracias e custos de aquisição de equipamentos. A maioria dos laboratórios de fabricação digital existentes no Brasil, 15 dos 22 mapeados por Sperling, Herrera e Scheeren (2015), estão conectados a instituições de pesquisa e universidades, tendo menos de 3 anos de existência. Nos laboratórios ligados às escolas de arquitetura, a maior parte trabalha explorando possibilidades de design e de produção digital, fabricando modelos em escala como forma de se aprender a utilizar novas ferramentas de design e rotinas de produção, reproduzindo a trajetória dos laboratórios na Europa e Estados Unidos. Esse processo de imitação reforça as relações de inovação entre centro e periferia, tendo em vista que nos países centrais a tecnologia aparece como uma resposta a determinadas circunstâncias, e na periferia a tecnologia é implementada como um símbolo de progresso e aparente modernidade, desconectada da realidade local. 
Para Arantes (2012), quando uma inovação ocorre sua difusão é sempre lenta, por causa da especialização crescente, dos códigos que regem a prática, dos procedimentos padronizados e da defesa das práticas tradicionais. Mas para David Gann $\left(1991^{8}\right.$ apud ARANTES, 2012), o papel de catalizadores da mudança assumidos pelos arquitetos é central para romper o sistema travado e refratário das inovações técnicas. Para Gann, o uso das ferramentas digitais deve transcender as experimentações formais, para trabalharem no sentido de uma reordenação de todo o processo produtivo. Sendo assim, para que ocorra uma mudança de paradigma no setor da construção civil por meio das tecnologias digitais, o campo arquitetônico a ser explorado deve transcender a produção restrita (simbólica), para abarcar uma produção de massa (dominada pelo capital econômico).

Caso os arquitetos assumam o controle da produção por meio das novas relações estabelecidas pela fabricação digital, as conexões entre firmas deveriam ser revistas. As ferramentas digitais emergentes possibilitam em projeto a evolução da forma representada digitalmente para a forma gerada digitalmente, em que o computador é utilizado de maneira a se explorar possibilidades. Essas novas possibilidades criadas por ferramentas digitais de projeto combinadas com ferramentas de análise de desempenho ${ }^{9}$ propiciam que a concepção do projeto demande a participação do engenheiro desde as etapas de concepção, diluindo as relações convencionais de autoria (OXMAN; OXMAN, 2010).
Para Fabricio (2002), a questão crucial para a mudança de paradigmas no desenvolvimento de produtos na construção civil é não somente as relações entre os agentes de projeto, mas a forma de integração desses agentes e o modelo de colaboração vigente. Na fabricação digital ocorre uma mudança de paradigma com relação ao modelo de desenvolvimento do processo de projetos e de fabricação e montagem de produtos, pois esse é o resultado do trabalho conjunto de engenharia e arquitetura (projeto baseado em desempenho), visto que os componentes são fabricados de maneira direta entre os arquivos gerados no computador e a produção nas máquinas de controle numérico (CNC), sem intermediários entre projeto e produção. Sendo assim, a fabricação digital possibilita que o arquiteto retome o controle da produção de produtos conforme afirma Kolarevic (2003). Mas para avaliar se essas mudanças também ocorrerão nos processos do canteiro no sentido de se criar novas maneiras de integração entre os agentes e se romper com as formas de relação do paradigma da manufatura, serão analisadas as possíveis relações a serem construídas entre os agentes da construção com o uso da fabricação digital (Figura 4).

\footnotetext{
${ }^{8}$ GANN, D. New Management Strategies and the Fast-Track Phenomenon. In: RAINBIRD, H.; SYBEN, G. (Orgs.). Restructuring a Traditional Industry: construction employement and skills in Europe. Nova York: Berg, 1991.

${ }^{9}$ As ferramentas digitais a que o texto se refere são os softwares que propiciam a criação de geometrias baseadas em relações paramétricas e algorítmicas por meio de sistemas generativos. Atualmente, os principais softwares que trabalham desse modo são o Rhinoceros juntamente com o plugin Grasshopper; e o Revit em associação com o Dynamo (Autodesk). Juntamente com esses softwares podem ser utilizadas ferramentas de simulação física (conforto ambiental e desempenho estrutural).
} 
Figura 4 - Possibilidades da fabricação digital na construção civil baseada nas conexões de Pavitt $(1984)^{10}$

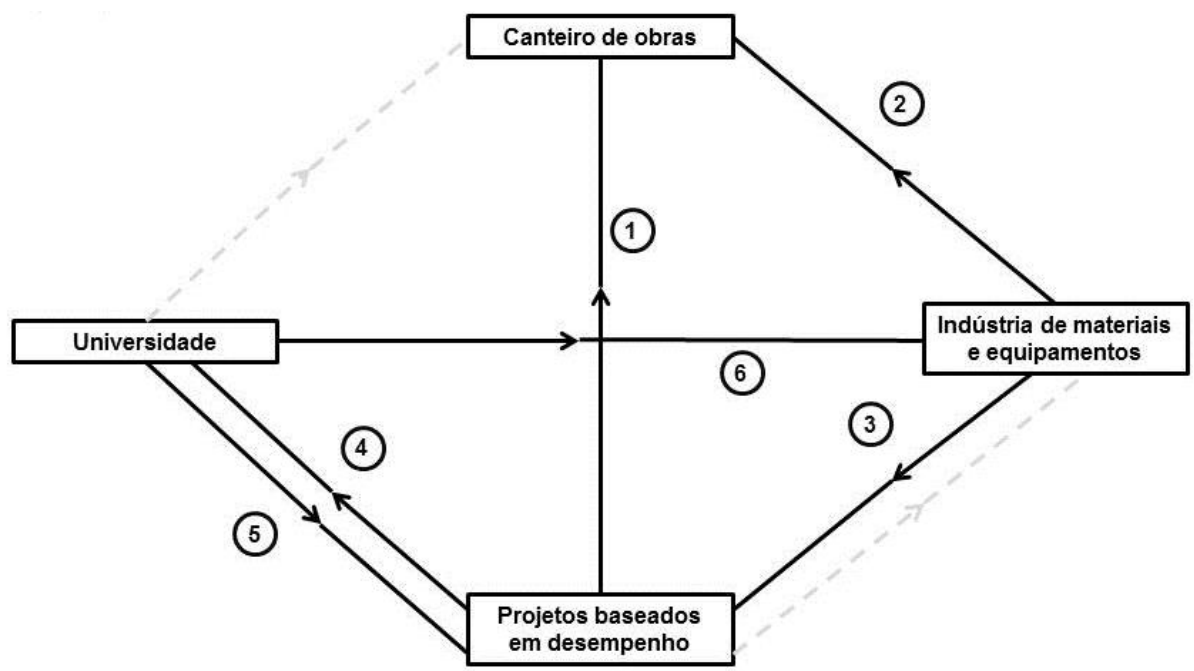

1 Produção de componentes no canteiro com máquinas CNC (fabricação digital)/ Projetos de arquitetura orientam a construção da forma (manufatura)

2 Fornecimento de materiais e equipamentos (manufatura)

3 Projetos de arquitetura especificam materiais existentes na indústria

4 Desenvolvimento de novas metodologias de projeto e novos softwares

5 Universidade absorve e desenvolve novas tecnologias e fornece mão-de-obra especializada para o mercado

6 Universidade desenvolve novos materiais para melhoria de desempenho e novos equipamentos para melhoria de produção

Fonte: desenvolvido a partir da figura de Pavitt (1984).

Na fabricação digital a principal mudança seria na relação do projeto com o canteiro. Com a instalação de máquinas de controle numérico (CNC) no próprio canteiro, não haveria intermediários entre o projeto de arquitetura e a produção no local. Dessa maneira, seria fundamental a presença do arquiteto auxiliando a mão de obra para orientar o corte e a produção de componentes customizados, bem como a montagem. Um exemplo disso é a aplicação da fabricação digital no canteiro de obras da Sagrada Família, em Barcelona. A tecnologia é utilizada para a produção das formas de concreto moldado in loco, que apresenta a maior dificuldade de execução pela complexidade das formas. Mas, embora toda a obra pudesse ser concebida com máquinas $\mathrm{CNC}$, as demais etapas da obra ainda são feitas por métodos mecanizados convencionais (CELANI; ORCIUOLI, 2008). Arantes (2012) enfatiza a predominância de canteiros híbridos em obras construídas em países centrais que já utilizaram essa tecnologia, em que processos artesanais são combinados com processos de fabricação digital. Sendo assim, no contexto brasileiro é difícil pensar em canteiros unicamente digitais devido às características já mencionadas do paradigma de produção atual. Com a presença da manufatura nesse contexto, as relações estabelecidas entre projetistas, indústrias e canteiro seriam praticamente inalteradas, sendo a produção digital um processo a parte dentro da manufatura. Uma possível mudança de relação com a indústria ocorreria caso a universidade (nesse caso as escolas de arquitetura) investissem em pesquisa de novos materiais e equipamentos, como já acontece em universidades dos países capitalistas centrais.

Outra mudança significativa seria na relação entre os projetistas e a universidade. No paradigma atual do ensino de projeto, a universidade se concentra em estudar tipologias arquitetônicas (produtos). No paradigma da fabricação digital as atenções ao se estudar uma obra se voltam para uma reengenharia dos processos para o desenvolvimento do projeto e da construção no canteiro. Os projetos baseados em desempenho e sua construção apresentam características de uma inovação econômica mais forte do que as inovações realizadas pela engenharia no paradigma atual, pois segundo Pavitt (1984, p. 366),

\section{[...] as trajetórias tecnológicas mais fortes ocorrem quando a inovação é orientada para o aumento do desempenho do produto, e menos forte quando é orientada somente para uma redução de custos [...].}

Com a formação de mão de obra dentro de uma nova perspectiva de produção de processos e produtos na arquitetura, seria possível que os

${ }^{10}$ Para este quadro considera-se o trabalho conjunto de arquitetura e engenharia na universidade. 
projetistas viessem a desenvolver materiais e equipamentos para a indústria, restabelecendo uma conexão de mão dupla com esse agente. Para Silva et al. (2009), a incorporação dos recursos de fabricação digital aos processos de projetação e construção de edificações no Brasil é significativamente mais lenta e recente que em outros países, e essa dificuldade não é resultante de uma ausência de recursos. Segundo Barbosa Neto (2013), o parque industrial brasileiro já está preparado para isso e sua apropriação pelos arquitetos depende apenas da formação de profissionais capacitados a explorar a tecnologia disponível.

Outra conexão fundamental a ser reestabelecida para que haja uma mudança de paradigma seria a ligação entre a universidade e o canteiro. A pesquisa em engenharia com relação à produção visa a redução de custos por intermédio de processos que otimizem a produção sem considerar que isso represente uma mais-valia da mão de obra. O papel da arquitetura é fundamental no sentido de se repensar de uma maneira social as relações desenvolvidas no canteiro.

\section{Papel da universidade para uma mudança de paradigma}

A inovação está sempre vinculada à incerteza, que muitas vezes envolve custos elevados. Em alguns setores, a universidade é a única instituição capaz de uma mudança de paradigma, por meio de pesquisa e preparo de mão de obra, promovendo uma rápida difusão do conhecimento. Para Nelson (1959), a universidade está no interior de uma percepção do progresso tecnológico como um processo "coletivo, cumulativo e evolucionário".

Os laboratórios de fabricação digital no Brasil vêm sendo utilizados predominantemente para o ensino e pesquisa nas escolas de Arquitetura. Neste momento, existe uma grande troca global de conhecimento, por meio de eventos e comunidades virtuais que ajudam a difundir a tecnologia. Para a entrada em um novo paradigma, é necessário que se faça um aproveitamento dessas "janelas de oportunidades", em que o custo de entrada é menor e o conhecimento não está patenteado. Neste momento as universidades são detentoras do conhecimento, o que facilita a entrada de países periféricos. Com o amadurecimento do paradigma, o conhecimento se tornará privado. A entrada em um segundo momento, ou seja, quando o paradigma já estiver consolidado em países centrais, diminuiria os riscos que envolvem a inovação, mas elevaria os custos de aquisição da tecnologia.
A pesquisa universitária normalmente é importante quando novas descobertas científicas influenciam diretamente a inovação industrial. $\mathrm{O}$ avanço do conhecimento científico provê uma expansão de teorias, dados, técnicas e capacidade de resolução de problemas. Novas possibilidades tecnológicas são abertas, propondo novas soluções para problemas antigos.

O professor Marcelo Tramontano (2016), do grupo Nomads da USP, relata a experiência do uso de ferramentas paramétricas e produção digital de protótipos em disciplinas de projeto. Para ele, a incorporação dessas ferramentas ao ensino implica em mudanças de postura didático-pedagógicas, projetuais, arquitetônicas e construtivas. Os alunos passam a compreender relações múltiplas entre processos de projeto e produção, já que a modelagem física e a preparação para fabricação, produção e montagem antecipam questões produtivas, construtivas e de organização da obra. Os alunos passam a consultar especialistas e fornecedores reais, buscando a viabilidade de se utilizar maquinário industrial digital no arranjo produtivo local e regional. Sendo assim, os arquitetos viram propositores de demandas a empresas que já dispõem de maquinário de fabricação digital, mas ainda não são utilizados para a produção de componentes para o setor da construção civil.

Sperling, Herrera e Scheeren (2015) acredita que para a aplicação das expertises globais é necessário criar um diálogo mais próximo com as especificidades locais, ressaltando a importância de se considerar o contexto regional na exploração de novas tecnologias. Essa postura é fundamental para o desenvolvimento da pesquisa sobre fabricação digital no Brasil e na América Latina. As universidades estão investindo em maquinário e formação de mão de obra para se trabalhar dentro da perspectiva de uma nova tecnologia, o que, portanto, torna necessário que se faça uma reflexão crítica das abordagens que estão sendo utilizadas. Sendo assim, as universidades poderiam não apenas explorar a reconstrução de um discurso sobre a forma arquitetônica por meio de tecnologias digitais, mas também desenvolver pesquisas com materiais apropriados para o lugar e a repensarem alternativas sustentáveis de produção de componentes e das relações no canteiro.

\section{Conclusão}

Mediante análise das relações de produção no setor da construção civil no contexto brasileiro por meio das conexões propostas por Pavitt, podemos observar que no atual modo de produção em manufatura, os arquitetos deixaram de fazer 
importantes conexões com a indústria e com o canteiro, seja pelos escritórios de projeto ou pelas universidades. Na manufatura, principalmente na heterogênea, os engenheiros assumiram todas essas conexões, tendo obtido dessa forma uma posição de domínio e controle do canteiro. O problema disso é que a engenharia tende a repensar processos e formas de produção sobre o ponto de vista de se aumentar os lucros, o que para o canteiro só reforçam as relações de mais-valia com os trabalhadores.

A inovação tecnológica, por meio da fabricação digital, poderia alterar as formas de interação entre os agentes da construção civil, conforme pressupõe Kolarevic, porém, com o objetivo de promover não mais um aumento da produtividade pela mais-valia do trabalhador, mas desenvolver uma prática emancipatória, no sentido de construir um aprendizado que transforme processos e estruturas sociais que excluem a maior parte da população, criando relações solidárias por meio do desenvolvimento. Sem modificar as relações de produção, somente a importação da tecnologia de fabricação digital para o contexto brasileiro não representa uma verdadeira inovação nos processos do canteiro, o que legitima a crítica de Arantes de que seria somente uma ilusão acreditar que a importação de uma nova tecnologia seria capaz de mudar paradigmas. Para a efetiva mudança de paradigmas, a universidade tem papel fundamental na recriação de conexões com o canteiro e com a indústria, desenvolvendo pesquisa de processos e produtos que considerem o contexto local, e não apenas reproduzindo por um processo de imitação o que está sendo desenvolvido em países capitalistas centrais. Dessa maneira, a inovação de processos no canteiro só ocorreria com o desenvolvimento de uma tecnologia social de aplicação.

Assim, não podemos dizer que o arquiteto retomará em curto prazo o controle da produção simplesmente com o uso da tecnologia digital no canteiro. Mas, também não seria ilusório pensar que algumas mudanças possam ocorrer em longo prazo por meio de uma mudança de postura na formação de profissionais de arquitetura, mais engajados na produção e nas relações que estas ocasionam. Nesse caso, o projeto deveria ser concebido visando mecanismos de colaboração horizontal entre projetistas e construtores, de maneira integrada e democrática. Para que a fabricação digital represente uma mudança de paradigma na construção civil, ela deveria estar associada a uma mudança de processo produtivo no canteiro. Caso contrário, a tecnologia não representaria uma verdadeira inovação, mas apenas uma invenção tecnológica para a produção de componentes customizados, reproduzindo as mesmas relações da produção em manufatura.

\section{Referências}

ABRAMOVITZ, M. Thinking About Growth. Cambridge: Cambridge University, 1989.

ARANTES, P. F. Arquitetura na Era DigitalFinanceira: desenho, canteiro e renda da forma. São Paulo: Editora 34, 2012.

BARBOSA NETO, W. Do Projeto à Fabricação: um estudo de aplicação da fabricação digital no processo de produção arquitetônica. Campinas, 2013. Dissertação (Mestrado em Engenharia Civil) - Faculdade de Engenharia Civil, Arquitetura e Urbanismo, Universidade Estadual de Campinas, Campinas, 2013.

CASTRO, A. C.; CARVALHO, F.J. C. Progresso Técnico e Economia. Revista USP, São Paulo, v. 76, p. 26-33, dez./fev. 2007-2008.

CELANI, G.; ORCIUOLI, A. A Tecnologia

Desvenda Gaudí: a fabricação digital e o patrimônio histórico, uma visita ao canteiro de obras da Sagrada Família. Revista AU, São Paulo, v. 17, dez. 2008. Disponível em $<$ http://au.pini.com.br/arquiteturaurbanismo/177/artigo118594-2.aspx>. Acesso em: 14 maio 2016.

\section{FABRICIO, M. Projeto Simultâneo na}

Construção de Edifícios. São Paulo, 2002. Tese

(Doutorado em Engenharia Civil) - Escola

Politécnica, Universidade de São Paulo, São Paulo, 2002.

FARAH, M. F. S. A Temática do Processo de Trabalho e da Gestão no Campo de Estudos da Habitação. In: ENCONTRO ANUAL DA ASSOCIAÇÃO NACIONAL DE PÓSGRADUAÇÃO E PESQUISA EM CIÊNCIAS SOCIAIS, 18., Caxambu, 1994. Anais... Caxambu, 1994.

FREEMAN, C.; SOETE, L. The Economics of Industrial Innovation. 3. ed. Cambridge: The MIT Press, 1997.

\section{KOLAREVIC, B. Architecture in the Digital}

Age: design and manufacturing. New York: Spon Press, 2003.

KOURY, A. P. Arquitetura Construtiva: proposições para a produção material da arquitetura contemporânea no Brasil. São Paulo, 2005. Tese (Doutorado em Arquitetura e Urbanismo) - Faculdade de Arquitetura e Urbanismo, Universidade de São Paulo, São Paulo, 2005. 
MARX, K. O Capital: crítica da economia política. São Paulo: Círculo do Livro, 1996.

NELSON, R. (Ed.). National Innovation

Systems: a comparative analysis. New York:

Oxford: Oxford University, 1993.

NELSON, R. The Simple Economics of Basic Scientific Research. Journal of Political Economy, v. 67, n. 3, jun. 1959.

NELSON, R. What enables Rapid Economic Progress: what are the needed institutions?

Research Policy, New York, v. 37, p. 1-11, 2008.

NOBRE, T. M.; STOLFI, A.; REZENDE, D. G. Conversa com Sérgio Ferro. São Paulo: FAUUSP, 2002.

OXMAN, R.; OXMAN, R. (Eds.). The New

Structuralism: design, engineering and architectural technologies. London: Wiley, 2010.

PAVITT, K. Sectoral Patterns of Technical Change: towards a taxonomy and a theory, Research Policy, New York, v. 3, p. 343-373, 1984.

SCHUMPETER, J. A Teoria do

Desenvolvimento Econômico. São Paulo: Nova Cultural, 1985.

SEDREZ, M.; CELANI, G. A Forma Não Importa: entrevista com Arnold Walz. Vitruvius, São

Paulo, v. 15, n. 58.03, jun. 2014.
SHIMBO, L.Z. Habitação Social, Habitação de Mercado: a confluência entre Estado, empresas construtoras e capital financeiro. São Paulo, 2010. Tese (Doutorado em Arquitetura e Urbanismo) Faculdade de Arquitetura e Urbanismo, Universidade de São Paulo, São Paulo, 2010.

SILVA, F. N. et al. A Indústria da Construção Civil Está Pronta Para a Fabricação Digital e a Customização em Massa? Uma pesquisa sobre um caso brasileiro. In: CONGRESSO ANUAL DA SOCIEDADE IBERO-AMERICANA DE GRÁFICA DIGITAL: DO MODERNO AO DIGITAL: DESAFIOS DE UMA TRANSIÇÃO, 13., São Paulo, 2009. Anais... São Paulo: Universidade Presbiteriana Mackenzie, 2009.

SPERLING, D. M.; HERRERA, P. C.;

SCHEEREN, R. Migratory Movements of Homo Faber: mapping fab labs in Latin America. In CELANI, G.; SPERLING, D. M.; FRANCO, J. (Eds.). Computer-Aided Architectural Design: the next city - new technologies and the future of the built environment. Berlin: Springer-Verlag, 2015.

TRAMONTANO, M. Quando Pesquisa e Ensino se Conectam: design paramétrico, fabricação digital e projeto de arquitetura. Vitruvius, São Paulo, v. 16, n. 190, 1 mar. 2016.

Marina Ferreira Borges

Programa de Pós-Graduação em Arquitetura e Urbanismo, Escola de Arquitetura | Universidade Federal de Minas Gerais | Rua Paraíba, 697, Funcionários | Belo Horizonte - MG - Brasil | CEP 30130-140 | Tel.: (31)3409-8829 | E-mail: marinafborges@gmail.com

Revista Ambiente Construído

Associação Nacional de Tecnologia do Ambiente Construído

Av. Osvaldo Aranha, $99-3^{\circ}$ andar, Centro

Porto Alegre - RS - Brasil CEP 90035-190

Telefone: +55 (51) 3308-4084

Fax: +55 (51) 3308-4054

www.seer.ufrgs.br/ambienteconstruido

E-mail: ambienteconstruido@ufrgs.br 